\title{
FORMAÇÃO DE GESTORES ESCOLARES: A ATUALIDADE DE JOSÉ QUERINO RIBEIRO*
}

\author{
Vitor Henrique Paro**
}

\begin{abstract}
RESUMO: A pretexto da comemoração dos cem anos de nascimento de José Querino Ribeiro, procura-se recuperar pontos relevantes da obra desse importantíssimo autor dos estudos sobre administração escolar, no Brasil, incidindo sobre suposto paradoxo aí presente e destacando duas alternativas para a formação de dirigentes escolares: uma formação "técnica" específica, calcada nos princípios e métodos da empresa capitalista, com apelo "gerencial" e privilegiando as formas de controle do trabalho alheio, ou uma formação fundamentada no pedagógico e nas potencialidades da educação como prática democrática.
\end{abstract}

Palavras-chave: José Querino Ribeiro. Formação de dirigentes escolares. Administração escolar.

\section{SCHOOL ADMINISTRATORS TRAINING: \\ José Querino Ribeiro's TOPICALITY}

ABSTRACT: The celebration of José Querino Ribeiro's birthday centennial led this paper to rescue the relevant points in the work of this very important author of studies on school administration in Brazil. Its stresses the supposed paradox herein present and highlights two alternatives to train school administrators: one, specific and "technical", is grounded in the methods and principles of capitalist companies, with "managerial" appeal and

* Trabalho apresentado na Mesa Redonda "Do Pioneirismo de Querino Ribeiro à Gestão Escolar do Século xxı", durante o xxıI Simpósio Brasileiro de Política e Administração da Educação, realizado em Porto Alegre, de 11 a 14 de novembro de 2007 e promovido pela Associação Nacional de Política e Administração da Educação (ANPAE).

** Livre-docente em Educação e professor titular da Faculdade de Educação da Universidade de São Paulo (USP).E-mail:vhparo@usp.br 
strong emphasis on how to control someone else's work while the other is based on pedagogical foundations and the potential of education as a democratic practice.

Key words: José Querino Ribeiro. School administrators. Training. School Administration.

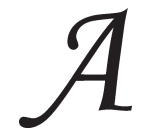

pretexto da comemoração dos cem anos do nascimento de José Querino Ribeiro, este artigo pretende recuperar pontos relevantes da obra desse importantíssimo autor dos estudos sobre administração escolar, no Brasil, estimulando a reflexão sobre o tema da formação dos dirigentes escolares.

Tomamos como base de referência suas duas principais obras: o estudo pioneiro sobre Fayolismo na administração das escolas públicas, ${ }^{1}$ de 1938, e o clássico Ensaio de uma teoria de administração escolar, ${ }^{2}$ de 1952.

Sem a pretensão de proceder a uma exegese da obra de José Querino Ribeiro, mas apenas de buscar aí elementos que contribuam para uma reflexão sobre a administração escolar, hoje, pode-se afirmar que existe pelo menos um paradoxo em tal elaboração teórica. Especialmente no Ensaio, ao mesmo tempo em que afirma a legitimidade de aplicação dos princípios da teoria geral de administração à situação escolar, Ribeiro oferece uma concepção de educação e de escola cujos objetivos são totalmente antagônicos aos da empresa capitalista em geral.

Reconhecendo a importância social da escola que, na sociedade moderna, tornou-se "um organismo altamente complexo" (Ribeiro, 1952, p. 39), esse autor mostra-se extremamente convencido da relevância da função dessa instituição na realização de uma política e de uma filosofia da educação e, por isso, enfatiza a necessidade de que tal função mereça o cuidado à altura de sua importância, para realizar-se o mais plenamente possível. É nesse contexto que a administração escolar, como mediação para a realização desse desiderato, se apresenta como uma questão de primeira grandeza. A esse respeito, Ribeiro segue a trilha teórica de A. Carneiro Leão que, já em 1939, no prefácio da primeira edição de sua obra Introdução à administração escolar, afirmava que "nenhum problema escolar sobrepuja em importância o problema de administração” (Leão, 1953, p. 13). 
Ressalte-se, portanto, na concepção de Ribeiro, a condição de mediação de toda administração: no que diz respeito especificamente à administração escolar, ele afirma que esta "é um instrumento para a realização dos objetivos da educação” (Ribeiro, 1952, p. 105). A riqueza teórica dessa visão de administração está no fato de que ela encerra aquilo que há de mais geral e abstrato num conceito rigoroso de administração, ou seja, o seu caráter mediador para realização de objetivos. Por isso que o conceito de administração, como síntese, pode ser expresso como "a utilização racional de recursos para a realização de fins determinados" (Paro, 1986, p. 18).

Nessa concepção de Ribeiro também se pode encontrar a raiz do possível paradoxo que estamos tentando explicitar. O primeiro termo desse paradoxo se apresenta na convicção do autor de que a administração escolar, para bem realizar-se, deve fundamentar-se nos estudos de administração geral. Isso está claro no Ensaio de uma teoria de administração escolar, em que ele pondera que

O Estado e as empresas privadas encontraram nos estudos de administração os elementos para remover suas dificuldades decorrentes do "progresso" social e a escola não precisou mais do que inspirar-se neles para resolver as suas. Acresce ainda que, sendo evidente a semelhança dos fatores que criam a necessidade dos estudos de administração pública ou privada, a escola teve apenas de adaptá-los a sua realidade. Assim, a ADMINISTRAÇÃO ESCOLAR encontra seu último fundamento nos estudos gerais de administração. (Ribeiro, 1952, p. 78)

Mais adiante, na mesma obra, ele declara expressamente: "A ADMINISTRAÇÃO ESCOLAR é uma das aplicações da administração geral; naquela como nesta os aspectos, tipos, processos, meios e objetivos são semelhantes" (p. 113).

O segundo termo do paradoxo configura-se na concepção de educação que Ribeiro apresenta e, portanto, do tipo de objetivo escolar cuja mediação cumpre à administração escolar propiciar. Ao expressar sua concepção de educação, ele declara:

No estado em que encontramos atualmente a teoria da educação, sentimo-nos obrigados a considerar o verbo "educar" como rigorosamente pronominal. O exato, pois, a nosso ver, é o "educar-se": "eu me educo"; "nós nos educamos". Realmente, o fenômeno da educação, em si mesmo, 
é puramente individual e psíquico [Lourenço Filho, Introdução ao estudo da escola nova], porque, ou o próprio indivíduo organiza e reorganiza suas experiências [John Dewey, Democracia e educação], ou ninguém poderá fazê-lo por ele. O fenômeno puro da educação é, portanto, a autoeducação, quer para as experiências bióticas, quer para as psíquicas, quer para as sociais. (Ribeiro, 1952, p. 14)

É fácil deduzir, dessa declaração, uma concepção de educação como formação do ser humano em sua integralidade de sujeito, de ser de vontade, autor de sua história, incompatível, portanto, com qualquer metodologia de ensino ou qualquer pedagogia que não leve em conta esse caráter ou que favoreça uma relação de dominação. Certamente, a administração escolar, como mediação para a realização dessa pedagogia e para a consecução dos objetivos que tal concepção de educação pressupõe, não pode contrariar tais fins e tais princípios pedagógicos, senão deixará de ser mediação, fazendo-se, em vez disso, obstáculo.

É aqui que se põe o caráter eventualmente paradoxal dos dois termos apresentados. De um lado, temos uma administração escolar que, ao buscar realizar os objetivos da escola, funda-se nos princípios e métodos da administração geral; de outro, apresenta-se a escola como formadora de sujeitos históricos, com objetivos incompatíveis com a dominação. Não haveria nada de contraditório ou paradoxal entre esses dois termos se o que se denomina "administração geral" se pautasse verdadeiramente pelos "princípios gerais de administração". Mas a chamada Teoria Geral da Administração, que se desenvolve a partir do início do século Xx, com Frederick Taylor (1978) e Henri Fayol (1981), e à qual José Querino Ribeiro se reporta (em especial a Fayol), sempre teve por referência a empresa mercantil capitalista. Não se trata, pois, de uma teoria geral, nem de princípios e métodos universais, já que seu objeto de estudo e o locus onde pretende aplicar-se são uma realidade específica, ou seja, a realidade da empresa capitalista, cujos métodos e princípios são compatíveis com a dominação e com a negação da condição de sujeito dos que são por ela subsumidos. Como pode, pois, aplicar-se à escola (uma instituição sabidamente do âmbito do diálogo e da afirmação de subjetividades, não da dominação) os mesmos princípios e métodos administrativos da empresa capitalista, sem que os meios contradigam os fins? Sem que, portanto, se negue o caráter mediador da administração anteriormente afirmado? 
Em outra ocasião (Paro, 2007), aventei a hipótese de que a existência desse paradoxo possa explicar o fato de a obra de Ribeiro ser aproveitada tanto por teóricos conservadores quanto por progressistas. Aqueles enfatizam o primeiro termo, procurando aplicar à escola os princípios e métodos da administração empresarial capitalista; os últimos apegamse ao segundo, relevando o caráter mediador da administração e propondo uma administração escolar que seja adequada aos fins especificamente democráticos da instituição educativa. Ambas as tendências se aproximam e se afastam ao mesmo tempo do pensamento de Ribeiro. A primeira se aproxima ao admitir princípios gerais para todo tipo de empresa, inclusive a educacional, mas se afasta ao deixar de reconhecer a especificidade do educativo, quando este se mostra contrário aos princípios e meios da empresa capitalista. A segunda se aproxima, ao reforçar o caráter democrático do objetivo educativo e a necessidade de alcançálo pela mediação administrativa, mas se afasta ao recusar-se a conceber a administração escolar à imagem e semelhança de qualquer empresa.

Dessas duas condutas, parece que a conservadora é a que mais se distancia e a que menos faz justiça ao pensamento de José Querino Ribeiro. Este, ao buscar princípios gerais de administração, o fazia com a intenção de prover a escola de instrumentos adequados para realizar mais plenamente seus fins democráticos e públicos, jamais com interesses privatistas de reduzi-la, em sua especificidade, a uma empresa capitalista. Examinando-se sua obra educacional, parece totalmente inadmissível sua concordância com procedimentos que contrariassem a vocação democrática e pública do ensino e da instituição escolar, como pretendem fazer aqueles interessados em "privatizar" a administração escolar com os modismos advindos da administração empresarial. Na obra de Ribeiro não deixa de haver momentos em que ele reconhece claramente uma especificidade da instituição escolar, merecedora de um tratamento diferenciado do da empresa comum, como quando ele afirma:

Considerando que na escola a ideia de autoridade tem um sentido particular, já porque a distância que separa os que devem comandar dos que devem ser comandados é muito pequena, já porque a educação moderna condena as velhas bases do "magister dixit", a função de comando tem, nela, um sentido próprio. A base das relações humanas na unidade ou no sistema escolar é a colaboração esclarecida e consentida e não a subordinação fundada na autoridade com força para se fazer 
Formação de gestores escolares: a atualidade de José Querino Ribeiro

obedecer ou se fazer crer. Com isso queremos dizer que, na escola, a ideia de comando esvazia-se dos elementos histórico-militares que lhe fossilizaram o sentido, prejudicando sua moderna e conveniente compreensão. (Ribeiro, 1952, p. 129)

Parece que a forma mais acertada de, senão resolver, pelo menos atenuar o paradoxo acima apontado é considerar a visão de empresa que perpassa o trabalho de Ribeiro. Embora os estudos críticos de Economia Política, a partir de Marx, tenham demonstrado que o objetivo da empresa privada (o lucro) só se realiza pela apropriação do trabalho excedente produzido pelo trabalhador, o que implica sua subordinação formal e real ao capital (Marx, [197-?]), isso não significa que Ribeiro tivesse consciência dessa visão ou concordasse com ela. Evidentemente, passa muito distante da visão apresentada por ele, em sua obra, o conceito de gerência capitalista como controle do trabalho alheio com o fim de expropriação, pelo capitalista, do valor excedente produzido pelo trabalhador (Braverman, 1980). Para ele, a empresa capitalista nem era qualificada como capitalista - era simplesmente "a empresa", que tinha um significado bastante geral. Diz ele, em Fayolismo na administração das escolas públicas: "Concluímos, pois, que uma empresa é um grupo de indivíduos agindo em conjunto sob uma certa hierarquia, com o fim de aliviar as dificuldades dos homens, aproximando-os em relações de solidariedade que facilitem o fim geral de todos - a conservação e desenvolvimento da espécie" (Ribeiro, 1938, p. 58). Em seguida, ao referir-se ao conceito de Vilbois e Vanuxen que "definem uma empresa como um grupo que se propõe atuar, sob uma certa hierarquia, para determinado fim" (p. 58, grifos originais.), Ribeiro afirma:

À primeira vista parece que o nosso conceito de empresa é muito mais amplo do que o de Vilbois-Vanuxen acima citados. Não o é, entretanto, porque eles, não determinando a natureza dos fins, incluem como empresa, também, os grupos que atuam para fins prejudiciais à humanidade. É assim que estão implicitamente incluídas na definição de Vilbois-Vanuxen as quadrilhas de todas as categorias. Discordamos disso porque não se concebe uma cousa humana intencionalmente organizada para prejudicar o homem, sem implicar grave e injustificável contradição. Daí considerarmos empresa somente os grupos que atuam com fim social útil, ou pelo menos, com semelhante intenção, conforme expusemos. (1958, p. 58) 
Perceba-se que Ribeiro sequer cogita incluir a empresa capitalista entre aquelas que se organizam "para prejudicar o homem". É bem verdade que o fim último do capitalista não é prejuízo do outro, mas o benefício próprio: o pensamento crítico é que consegue constatar que tal benefício se faz à custa do sacrifício do outro. Parece ser a falta desse pensamento crítico que leva Ribeiro a igualar a organização da empresa à da escola:

Os princípios de submissão do interesse particular ao geral, de centralização e descentralização, de ordem e de iniciativa e de equidade e união, encontram-se, por sua vez, com a mesma importância e os mesmos aspectos, seja na empresa industrial, seja na escolar. Mas, dum modo geral, todos são aplicáveis à escola, porque existe certa identidade de organização entre as empresas em geral e a escolar. (Ribeiro, 1938, p. 105)

Parece claro, portanto, que a intenção de Ribeiro, ao propor a aplicação, na escola, dos princípios e métodos da administração empresarial, era procurar formas de realizar aí, de maneira tão eficiente quanto se realizava o trabalho nas empresas, os importantes objetivos educacionais; não era transportar para a instituição escolar as técnicas e estratégias de dominação presentes na empresa tipicamente capitalista, cuja percepção crítica lhe escapava.

Isso, entretanto, não desobriga aqueles comprometidos com uma educação formadora do humano-histórico e portadores de uma concepção crítica da economia e da sociedade de levar em conta o tipo de relações sociais de dominação implícitas na empresa capitalista e de buscar formas democráticas de administrar a escola, sem a interferência do viés autoritário do capital.

Portanto, é possível, sim, fazer avançar a reflexão a respeito da organização e administração das escolas, aproveitando o contributo teórico de José Querino Ribeiro a esse tema, desde que se tenha presente sua visão de empresa, bem como a consciência dos limites impostos por sua concepção da sociedade capitalista. Tal compreensão se impõe para que se possa fazer uso com proveito das contribuiçóes que a atualidade de seu pensamento permite.

No que concerne à formação de gestores escolares, objeto deste trabalho, os termos do paradoxo anteriormente examinados apontam para duas posições bastante diferenciadas. A ruptura do paradoxo em 
Formação de gestores escolares: a atualidade de José Querino Ribeiro

favor de uma concepção "empresarialista" acena para uma formação "técnica” específica, sobreposta, paralela ou em substituição à formação pedagógica, mas calcada nos princípios e métodos da empresa capitalista, com apelo "gerencial" e privilegiando as formas de controle do trabalho alheio em favor de um objetivo particular exterior aos grupos comandados. Por sua vez, a solução do paradoxo pela afirmação do caráter democrático e emancipador da educação, com fins antagônicos ao mando e à submissão inerentes à produção capitalista, labora na direção de uma formação de dirigentes escolares fundamentada no pedagógico e nas potencialidades da educação como prática democrática.

Em Fayolismo na administração das escolas públicas, o próprio Ribeiro parece estar inteiramente de acordo com a ruptura do paradoxo em favor do termo "empresarial". Ao fazer a crítica à administração das escolas no estado de São Paulo, no final da década de 1930, afirma:

Outra seria entretanto a realidade, se tivéssemos tido para dirigentes uma formação à altura da que temos para os mestres. Até agora tem-se admitido que o melhor professor possa e deva ser o diretor dum estabelecimento, quando, na verdade, pode-se perfeitamente possuir todos os requisitos para um bom professor, sem possuir os necessários para administrador. Só com uma preparação especial é que se chegaria a verificar se de fato há conveniência na transposição de um cargo para outro. (Ribeiro, 1938, p. 70)

Propõe, por isso, uma carreira de administrador distinta da de professor e defende a "formação dos dirigentes em cursos especiais capazes de dar uma cultura e prática adequadas àquela função e estabelecimento de uma doutrina de administração que melhor corresponda às exigências da empresa escolar" (p. 71).

Essa maneira de ver a formação do administrador escolar parece tributária de sua concepção de coordenação. Na mesma obra, ao falar sobre a necessidade da coordenação, ele diz:

Dadas as condições normais em que as atividades se processam, há a exigência fundamental de uma coordenação, a fim de que a cooperação tenha menos falhas e insuficiências. É um poder corretivo que procura alcançar o melhor êxito possível e não existe senão [,] em a maioria dos indivíduos, o quanto baste para satisfazer as exigências de uma cooperação, desde certos limites em diante. E isto se explica pelo fato de ser 
a operação menos exigente do que a ordenação, para com o proporcionamento das forças que determinam as atividades. ( Ribeiro, 1938, p. 26 , grifos meus)

Essa concepção de coordenação parece por demais restrita, porque admite apenas uma maneira de organizar o esforço humano coletivo, que é muito mais uma mera ordenação (feita por meio de um elemento heteronômico, exterior ao grupo "coordenado"), do que uma co-ordenação, mais condizente com a autonomia e com a colaboração recíproca. Em meu livro Administração escolar: introdução crítica (Paro, 1986), apresento um conceito mais amplo de coordenação. Aí o conceito se refere à utilização racional do esforço humano coletivo, supondo que tal coordenação possa fazer-se tanto de forma impositiva - de um (ou uns) sobre outro(s) - quanto democrática - fazendo mais jus, esta, ao nome de co-ordenação. Neste último caso, não é uma autoridade exterior ao grupo, mas este mesmo que se organiza para coordenar o esforço de todos. Esse conceito de coordenação não menospreza a capacidade humana de agir politicamente, porque não a restringe à direção heterônoma na condução das atividades do grupo.

É preciso supor uma sociedade de humanos muito pouco desenvolvida politicamente para admitir que o alcance de objetivos por meio do esforço coletivo só se faça pela forma de uma direção monocrática das vontades, que se destaca acima do grupo dirigido. O ser humano, em vez disso, pode muito bem organizar-se politicamente, de maneira a que a direção seja a manifestação da vontade do próprio grupo, cuja coordenação, como o próprio termo indica, ${ }^{3}$ seja feita não sobre os dirigidos, mas com eles. E essa é a forma por excelência numa sociedade que pretenda fazer-se cada vez mais propícia ao florescimento da liberdade e da convivência dialógica e negociada entre pessoas e grupos que se afirmem como sujeitos, autores de suas histórias individuais e coletivas.

Mas Ribeiro, em sua obra de 1938, parece ver a necessidade de um "poder coordenador" que se sobreporia ao conjunto das pessoas envolvidas na busca de fins, até como uma "prevenção" a "imperfeição natural" dessas pessoas:

Se a ação humana se processa em cooperação, exigindo para a sua eficiência um poder coordenador preventivo das falhas naturais do indivíduo, segue-se que a sociedade não pode preencher a sua função de preservação 
Formação de gestores escolares: a atualidade de José Querino Ribeiro

e desenvolvimento da espécie, quando não contar com este agente que lhe garante desde a sua própria estabilidade.

Este poder coordenador dos grupos, tomando vários aspectos e nomes, segundo a amplitude e caráter de sua atuação, está sempre fundado no mesmo motivo - imperfeição natural dos individuos.

Administração é uma das formas deste poder, ou melhor, uma das maneiras de se exercê-lo e, como tal, necessidade imprescindível onde quer que se encontrem homens empenhados em obter, por meio de esforços conjugados, um certo objetivo interessante. (Ribeiro, 1938, p. 26, grifos meus)

Nesses três parágrafos, poder-se-ia imaginar, com uma considerável dose de boa vontade, que Ribeiro está-se referindo à coordenação e à administração in abstracto, desvinculada de qualquer forma concreta de exercê-las, com o poder de decisão emergindo ou não do próprio grupo coordenado. Essa interpretação, todavia, parece não corresponder àquilo que Ribeiro desenvolve mais adiante nesse mesmo trabalho, quando procura atribuir a cada função de coordenação a pessoa mais preparada para desempenhá-la.

(...) O esforço da organização consiste em criar as funções que mais favoreçam o alcance da meta proposta e dispor o elemento humano de forma que cada agente fique no lugar onde mais e melhor possa produzir, com atribuições bem definidas. Na empresa escolar, este esforço constituiria a escolha e criação das cadeiras necessárias e a dos profissionais existentes em melhores condições para desempenhá-las. (Ribeiro, 1938 , p. 85)

Não se trata, portanto, de uma coordenação abstrata que pode adquirir variadas formas concretas (tanto as heterônomas quanto as autônomas), mas da coordenação na única forma concreta, de alguém que tem o poder de administrar. Ribeiro desce do conceito geral de administração para entendê-la como simples forma de poder. E não se examinam aqui outras formas de coordenação. $\mathrm{O}$ administrador deve ter qualidades e funções diferenciadas dos demais. Na continuação do trecho anterior, ele afirma:

Deve-se fazer aqui uma observação importante: Não compete ao administrador conhecer, em suas minúcias, as condições para escolha destes elementos. Pensamos que isto seja uma função mais de técnica do que de 
administração. Assim, por exemplo, o gerente de uma indústria não tem necessidade de saber que tal máquina é mais ou menos eficiente para tal serviço, mas, apenas, saber que é preciso a máquina mais eficiente. $\mathrm{O}$ exame e julgamento deste ou daquele tipo compete ao técnico no assunto. No caso da empresa escolar, quando se trata de organização das classes, o administrador contaria, por exemplo, com um técnico em aplicação e avaliação de provas e testes. Se assim não fosse, chegaríamos ao ponto de exigir que o administrador fizesse tudo, quando, de fato, ele apenas deve saber a quem confiar cada tarefa (...). (Ribeiro, 1938, p. 85)

Perceba-se que há pessoas determinadas para comandar outras, cujo papel é (entre outros) obedecer. É certo que, em sua obra posterior, Ribeiro dirá, como vimos antes, que, "na escola, a ideia de comando esvazia-se dos elementos histórico-militares que lhe fossilizaram o sentido" (1952, p. 129). Mas também nesta obra não se prevê nenhum tipo de co-ordenação em que o grupo seja ao mesmo tempo objeto e sujeito da ação coordenadora. O que parece acontecer é que, mesmo admitindo uma concepção emancipadora de educação, entendida como constituição de sujeitos, o pensamento de Ribeiro ainda se faz refém da concepção de mundo dominante, que "naturaliza" as condições de dominação existentes, sem vislumbrar sua ultrapassagem com vistas a relações mais democráticas e mais humanas. Por isso, precisa recorrer a uma suposta "imperfeição natural" dos indivíduos para propor sua correção ou contenção, por meio de uma "coordenação" unilateral cuja imunidade contra "imperfeições naturais" (e históricas) ninguém garante.

Não é de estranhar que tal visão leve à proposição de uma formação diferenciada do dirigente escolar, porque supõe que só alguns possam ser dirigentes. Outra seria a sugestão se houvesse o entendimento de que o homem possui potencialidades políticas ilimitadas, entre elas a de conviver democraticamente, com a autoridade perpassando todas as instâncias do grupo, que se faz sujeito, sem necessariamente encarregar uma pessoa ou instância de vigiá-lo para que ele aja harmonicamente, de modo a atingir os objetivos comuns. Neste caso, não apenas alguns, mas todos, presumivelmente, devem deter as aptidóes políticas e técnicas necessárias ao dirigente.

Em nossa escola básica, vivemos uma situação em que o cargo ou função de diretor paira sobre as demais funçóes docentes e não-docentes da escola, com uma autoridade que coloca o dirigente escolar acima dos demais. Em consequência, suas aptidões administrativas - 
Formação de gestores escolares: a atualidade de José Querino Ribeiro

tanto técnicas (capacidade para planejar e organizar as ações, e utilizar racionalmente os recursos disponíveis) quanto políticas (liderar o grupo e coordenar o esforço humano coletivo) - são consideradas bastante específicas e diferenciadas dos demais integrantes da unidade escolar, reclamando uma formação profissional inicial também diferenciada.

Entretanto não é necessário que seja assim, isto é, não há nada que exija a presença de um único diretor a comandar todos os demais na escola. Embora isso seja cômodo ao Estado, em termos de controle da escola - que tem no diretor único não apenas o responsável último, mas também o culpado primeiro por tudo que aí desagrade aos interesses do Estado -, nada impede que se concebam formas coletivas de gestão escolar, mais afinadas com os objetivos educativos (por isso democráticos) que se pretende atingir. Em vez de um diretor, pode-se pensar em um conselho diretivo eleito (cf. Paro, 2008), composto por três ou quatro coordenadores que (de fato) representem a escola diante do Estado, sem que nenhum detenha sozinho a responsabilidade por seu funcionamento.

Esse novo modelo exige outra concepção de formação inicial para os dirigentes escolares, alargando enormemente o número daqueles que precisam de uma formação consentânea com a função administrativa. Tal aumento não se dá apenas porque cresce o número de dirigentes - que deixa de ser individual para ser um colegiado -, mas também porque, superados os modos tradicionais (e inadequados) de provimento do posto de diretor, que não promovem o comprometimento deste com seus dirigidos - o burocrático concurso e a clientelista nomeação político-partidária -, agora todos os educadores escolares são virtuais candidatos à função diretiva, porque cada um deles pode ser um eventual candidato ao posto de coordenador. A consequências é que todos devem ter formação administrativa.

Mas há outro motivo muito forte para que todos na escola devam ter formação administrativa. E este se fundamenta no pensamento de Ribeiro de que a administração é mediação para o alcance de fins. Diz respeito ao fato de que o processo de buscar fins, na escola, não se restringe às atividades-meio, mas perpassa todo o processo, mostrando sua importância precisamente na realização das atividades-fim. $\mathrm{O}$ pensamento que restringe a formação administrativa ao diretor supóe que só as atividades-meio são consideradas administrativas, como se apenas elas precisassem se fazer mediação para o alcance de fins. Disso decorre 
a tendência de prover o diretor de habilidades, conhecimentos e competências que só ele precisaria ter. Esta é uma forma de pensar a formação dos educadores escolares que não toma o pedagógico como objeto de estudo da administração, e com isso deixa o processo incompleto, alijando o pensamento administrativo escolar de uma de suas partes mais importantes, porque não pensa a atividade-fim, o processo pedagógico, como realmente é, como atividade adequada a objetivos que precisam ser racionalmente mediados.

Esse percurso que vai do administrativo para o pedagógico deve completar-se com o percurso inverso, que vai do pedagógico para o administrativo. Do mesmo modo que a administração enriquece a prática pedagógica, provendo-a de racionalidade na busca de fins, a prática administrativa pode ser enriquecida pela relação pedagógica, na medida em que esta seja entendida como prática democrática.

Se, como o próprio Ribeiro admite, educar é verbo "rigorosamente pronominal" (mais do que isso, diríamos, educar é verbo reflexivo), de tal modo que "o próprio indivíduo organiza e reorganiza suas experiências" (1952, p. 14), então a educação é um fenômeno que depende da vontade do próprio educando, consistindo a própria Didática, ao fim e ao cabo, nos meios que se utilizam e nas condiçóes que se desenvolvem para levar o educando a querer aprender. A formação do educador, portanto, precisa prepará-lo no mister político de produzir a concordância do outro na apropriação da cultura, o que significa, já, levar em conta componentes intrinsecamente relacionados à formação do administrador escolar, em especial ao que se refere à coordenação do esforço humano coletivo. Quem tem capacidade para levar o aluno a querer aprender, terá, sem dúvida, melhores condições para levar seus colegas educadores a querer ensinar e para co-ordená-los no processo de realização de objetivos.

Recebido em dezembro de 2007 e aprovado em abril de 2008.

\section{Notas}

1. Em 1938, José Querino Ribeiro era, há dois anos, assistente da Cadeira de Administração e Legislação Escolar do Instituto de Educação da USP. No momento em que, no cenário externo, avizinhava-se a eclosão da II Guerra Mundial e, internamente, o Brasil passava pela ditadura do Estado Novo, com Getúlio Vargas, Ribeiro publicava sua primeira obra de grande importância: Fayolismo na administração das escolas públicas. Já 
Formação de gestores escolares: a atualidade de José Querino Ribeiro

fazia seis anos que os pioneiros da Escola Nova tinham lançado seu manifesto à nação, alertando para a importância da educação no desenvolvimento da sociedade e na constituição da cidadania. O livro de Ribeiro fazia eco a essas idéias, ao assumir que a relevância da educação justificava todo esforço em bem administrá-la para alcançar os resultados almejados. No campo especificamente técnico-administrativo, ao tempo em que, tanto no Brasil quanto no exterior, ainda predominava uma concepção de gestão educacional e de direção de escolas fundamentada nos relatos de experiências exitosas, no âmbito do bom senso e das experiências pessoais do dia-a-dia, Ribeiro propunha um tratamento científico da administração, indo buscar sua inspiração nas teorias da administração empresarial, mais especificamente nas idéias de Henri Fayol (1989).

2. Ensaio de uma teoria de administração escolar, publicada pela primeira vez em 1952 , constituiu a tese com que José Querino Ribeiro foi aprovado no concurso para provimento do cargo de catedrático da então Cadeira de Administração Escolar e Educação Comparada da antiga Faculdade de Filosofia, Ciências e Letras da Universidade de São Paulo. Nessa ocasião, o Brasil experimentava um período de democracia, no interregno entre o Estado Novo e o golpe de 1964. Desde 1946, discutia-se no Congresso o projeto da primeira Lei de Diretrizes e Bases da Educação Nacional, que viria a ser aprovada e promulgada apenas em 1961, período rico em debates em torno da defesa do ensino público para todos. A obra pioneira de José Querino Ribeiro teve grande repercussão no mundo acadêmico e passou a influenciar especialmente os cursos de formação de administradores escolares. A partir de sua nova versão (1978), atualizada e ampliada por João Gualberto de Carvalho Meneses (Ribeiro, 1978), continuou sendo referência importante, adotada largamente nas habilitaçóes de Administração Escolar dos cursos de Pedagogia.

3. O prefixo "co-", de acordo com o Dicionário Etimológico Nova Fronteira da Língua Portuguesa (Cunha, 1982, p. 190), deriva do vocábulo latino cum, "que designa 'companhia, contiguidade, sociedade' (...)".

\section{Referências}

BRAVERMAN, H. Trabalho e capital monopolista. 2. ed. Rio de Janeiro: Zahar, 1980.

CUNHA, A.G. Dicionário etimológico Nova Fronteira da lingua portuguesa. Rio de Janeiro: Nova Fronteira, 1982.

DEWEY, J. Democracia e educação. São Paulo: Nacional, 1936.

FAYOL, H. Administração industrial e geral. 9. ed. São Paulo: Atlas, 1981.

LEÃO, A.C. Introdução à administração escolar: para as escolas de professores dos institutos de educação, universidades e faculdades de filosofia, ciências e letras. 3. ed. São Paulo: Nacional, 1953. [1. ed. em 1939] 
LOURENÇO FILHO, M.B. Introdução ao estudo da escola nova. São Paulo: Melhoramentos, 1930.

MARX, K. O capital. Rio de Janeiro: Civilização Brasileira, [197-?] Livro 1.

PARO, V.H. Administração escolar: introdução crítica. São Paulo: Cortez, 1986.

PARO, V.H. Estrutura da escola e educação como prática democrática. In: Correa, B.C.; Garcia, T.O. (Org.). Politicas educacionais e organização do trabalho na escola. São Paulo: Xamã, 2008. p. 11-38.

PARO, V.H. José Querino Ribeiro e o paradoxo da administração escolar. Revista Brasileira de Política e Administração da Educação, Porto Alegre, v. 23, n. 3, p. 561-570, set./dez. 2007.

RIBEIRO, J.Q. Fayolismo na administração das escolas públicas. São Paulo: Linotechnica, 1938

RIBEIRO, J.Q. Ensaio de uma teoria da administração escolar. São Paulo: FFCL/UsP, 1952. (Administração escolar e educação comparada; boletim 158)

RIBEIRO, J.Q. Ensaio de uma teoria de administração escolar. Ed. rev., anot. e ampl. por João Gualberto de Carvalho Meneses. São Paulo: Saraiva, 1978.

TAYLOR, F.W. Princípios de administração científica. 7. ed. São Paulo: Atlas, 1978. 